\title{
RE-EVALUATION OF THE RAMMSONDE HARDNESS EQUATION
}

\author{
By R. W. WAterhouse
}

(U.S. Army Cold Regions Research and Engineering Laboratory, Hanover, New Hampshire, U.S.A.)

\begin{abstract}
Penetration tests in snow show that the Rammsonde number $\bar{R}$ as a measure of force resisting penetration may be in error by a factor of two depending on the ratio of hammer to probe weight and the coefficient of restitution. It is suggested that the Hiley pile driving formula is applicable to the problem and gives more accurate values for the force of penetration. This formula accounts for the influence of different hammer weights, is in agreement with the conservation laws to the first approximation, and has been in general use for some time as one of the best simple equations for determining the dynamic resistance of piles.

The Rammsonde equation is notable for its simplicity. The Hiley equation, using the same factors does not detract from this virtue. Further research is suggested to find ways of replacing the coefficient of restitution with more fundamental parameters in impact problems.
\end{abstract}

RÉsumé. Evaluation de l'équation de dureté de la sonde de battage. Des essais de pénétration dans la neige montrent que le nombre $\bar{R}$ de la sonde de battage, mesure de la force résistant à la pénétration, peut présenter une erreur d'un facteur deux dépendant du rapport du poids de battage à celui de l'échantillon et au coefficient de restitution. Il est suggéré que la formule de pénétration de Hiley est applicable au problème et donne de meilleures valeurs de la force de pénétration. Cette formule tient compte des différents poids de battage, est en accord avec les lois de conservation pour la première approximation et a été utilisée largement depuis un certain temps comme l'une des meilleures équations simples pour déterminer la résistance dynamique des pieux.

L'équation de la sonde de battage est notable pour sa simplicité. La formule de Hiley, qui utilise les mêmes facteurs, ne déroge pas à cet qualité. Il est suggéré que des recherches futures trouvent le moyen de remplacer le coefficient de restitution par des paramètres plus fondamentaux pour les problèmes de
pénetration.

Zusammenfassung. Betrachtungen zur Härtegleichung für Rammsonden. Durchdringungsversuche in Schnee zeigen, dass die Rammsonden-Zahl $\bar{R}$ als Mass für den Widerstand gegen Durchdringung um den Faktor 2 unsicher sein kann, in Abhängigkeit von dem Verhältnis zwischen den Gewichten von Hammer und Sonde und dem Restitutionskoeffizienten. Es wird angenommen, dass Hileys Formel für das Einbringen von Pfählen auf das Problem anwendbar ist und die Durchdringungskraft mit grösserer Genauigkeit liefert. Diese Formel berücksichtigt den Einfluss verschiedener Hammergewichte, ist in erster Annäherung mit den Erhaltungssätzen im Einklang und wurde für einige Zeit allgemein als eine der besten einfachen Gleichungen zur Bestimmung des dynamischen Widerstandes von Pfählen benutzt.

Die Rammsondengleichung ist wegen ihrer Einfachheit bemerkenswert. Die Hiley-Gleichung, die dieselben Faktoren benutzt, steht ihr in dieser Tugend nicht nach. Weitere Untersuchungen werden vorgeschlagen, um Wege zum Ersatz des Restitutionskoeffizienten durch fundamentalere Parameter bei Eindring-Problemen zu finden.

A VIRTUE of the Rammsonde test for hardness is its simplicity of performance and evaluation. If this simplicity is lost, the principal value of this test is impaired. A limitation is therefore placed on methods of improving the effectiveness of the system; however, poor correlation of test results indicates that an improvement in the analysis is needed. written

The dynamic portion of the original Rammsonde equation (Bader and others, I939),

$$
\bar{R}=\frac{W_{\mathrm{H}} h}{S}
$$

assumes a coefficient of restitution of unity as a convenience. The entire potential energy of the system is transformed into some mean force $(\bar{R})$, traversing a distance $(S)$, which is the permanent penetration per blow. The kinetic energy available is presumed to be equal to the potential energy $W_{\mathrm{H}} H$ of the hammer of weight $W_{\mathrm{H}}$ at height $h$ above the point of impact. If the concept of the mean force $\bar{R}$ persisting during the penetration is to be maintained as in equation ( $\mathrm{I}$ ), it can be stated: (i) that equation ( $\mathrm{I}$ ) will indicate a force up to twice its actual value (as is indicated below by equation (8)); (ii) tests where the potential energy is held constant and the weight of hammer $W_{\mathrm{H}}$ and probe $W_{\mathrm{P}}$ are changed will give different 
hardness values for the same material. Tests by Niedringhaus (1965) demonstrate this as shown in Figure $\mathrm{I}$.

The graphs show mean hardness for each $5 \mathrm{~cm}$. penetration. Each value is the average of I2 tests in snow of uniform composition. Note that as $W_{\mathrm{H}}$ increases, $R$ decreases and as $W_{\mathrm{P}}$ increases, $R$ increases. Since virtually the entire force of penetration is inertial,

$$
F=\bar{R}-\left(W_{\mathbf{H}}+W_{\mathbf{P}}\right),
$$

it can be shown that the mass in motion after impact will determine the energy available and transferable to the resistance to displacement $\bar{R}$. Therefore tests for correlation should start with a constant kinetic energy after impact. In providing this information it would be seen
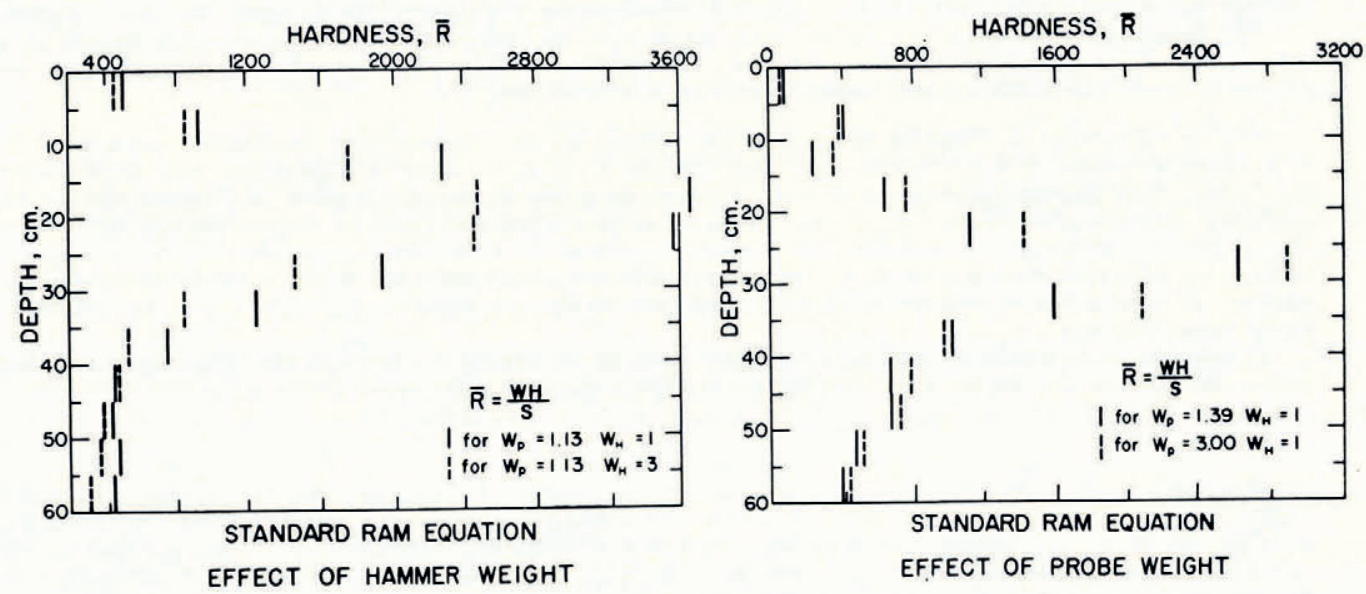

Fig. I. Values of the ram hardness obtained by Niedringhaus $(1965)$ calculated using the usual Rammsonde formula. Each value is the average of $I 2$ tests in snow of uniform composition. In the left-hand diagram tests using two different hammer weights are compared, in the right-hand diagram two different probe weights are compared

that both the weight ratio $W_{\mathrm{H}} / W_{\mathrm{P}}$ and the coefficient of restitution $e$ must be known and expressed in the equation of force. Haefeli and Brandenberger (unpublished) proposed an expression to account for these conditions:

$$
\begin{gathered}
\bar{R}=\frac{W_{\mathrm{H}} h}{S} \lambda \\
\lambda=\frac{W_{\mathrm{H}}+e^{2} W_{\mathrm{T}}}{W_{\mathrm{H}}+W_{\mathrm{T}}}
\end{gathered}
$$

where $W_{\mathrm{T}}=W_{\mathrm{H}}+W_{\mathrm{P}}$.

It is not the absolute magnitude of the hammer weight that alters the hardness number for a given material but the relative weight ratio of the hammer and probe, which in the first analysis agrees with the results of the Niedringhaus tests.

Since the Rammsonde is a miniature pile and driver we can expect to find a similar problem in soil mechanics in the pile driving literature. Referring to Chellis (I95I) and Henry (1956), we find a derivation for this problem which is entirely applicable, since the components of the equipment are in the same terms, the behaviour of the resisting medium is represented by $R$, the resistance to dynamic penetration and $S$, the penetration per blow from a drop hammer, and $e$, the coefficient of restitution, is an experimentally determined constant as defined. 
This derivation in brief is as follows:

Assume

(i) The pile is able to move, and

(ii) The pile remains loose in the soil.

Let $v$ be the velocity of the hammer due to free fall and $v_{\mathrm{H}}$ the velocity of the hammer at the end of the period of restitution, then

$$
v_{\mathrm{H}}=v \frac{W_{\mathrm{H}}-e W_{\mathbf{P}}}{W_{\mathrm{H}}+W_{\mathbf{P}}},
$$

while the velocity of the probe $v_{\mathrm{P}}$ at end of period of restitution

$$
v_{\mathrm{P}}=v \frac{W_{\mathrm{H}}+e W_{\mathrm{H}}}{W_{\mathrm{H}}+W_{\mathrm{P}}} .
$$

The maximum available energy at end of restitution period is

$$
\frac{W_{\mathrm{H}} v_{\mathrm{H}^{2}}^{2}}{2 g}+\frac{W_{\mathrm{P}} v_{\mathrm{P}}^{2}}{2 g}=W_{\mathrm{H}} h\left[\frac{W_{\mathrm{H}}+e^{2} W_{\mathrm{P}}}{W_{\mathrm{H}}+W_{\mathrm{P}}}\right] .
$$

The coefficient of energy transfer being

$$
\begin{gathered}
\frac{W_{\mathrm{H}}+e^{2} W_{\mathrm{P}}}{W_{\mathrm{H}}+W_{\mathrm{P}}} \\
\bar{R}=\frac{W_{\mathrm{H}} h}{S}\left[\frac{W_{\mathrm{H}}+e^{2} W_{\mathrm{P}}}{W_{\mathrm{H}}+W_{\mathrm{P}}}\right] .
\end{gathered}
$$

This is the basic term in the Hiley (1925) formula for pile driving.

It is of interest to note that the equation may apply more accurately to the ram test than to piles because of the assumption that "the pile remains loose in the soil". The Rammsonde characteristically remains loose in the hole.

To test the effectiveness of these expressions in providing better correlation of data from tests where different weights were used and in providing a hardness number of more universal significance, data from the Niedringhaus (1965) tests in high-density snow have been used for plotting the standard equation, the Haefeli equation, and equation (8) (Figs. I, 2 and 3 ).

Figure I shows the results of using the original ram equation. Poor correlation occurs between results for either a high hammer weight or a high probe weight and those where the weights were almost equal. The hammer effects tests were conducted 3 days after the probe effects tests in an active (mechanically disaggregated) snow which could readily account for the obvious difference in hardness profiles for the two tests, which does not influence the effects being studied.

Figure 2 shows results using the Haefeli equation. Better correlation occurs but values for hardness are radically reduced.

Figure 3 shows equation (8) as the Hiley formula. Correlation between data for the $\mathrm{I} \mathrm{kg}$. and the $3 \mathrm{~kg}$. hammer is better than for either the standard equation or the Haefeli equation.

Although the Haefeli equation gives better correlation for the effect of probe weight, the absolute values are believed low. It is expected that when the problem is studied further a reduction of the restitution coefficient will result.

Since the standard Rammsonde kit includes the $\mathrm{I}$ and $3 \mathrm{~kg}$. hammers, results using these hammers are most likely to be compared. The Hiley formula appears to be the most useful for comparisons within this range. The Hiley formula is also compatible with the conservation of energy and momentum equations to the first approximation, a claim that cannot be made for the Haefeli equation. 

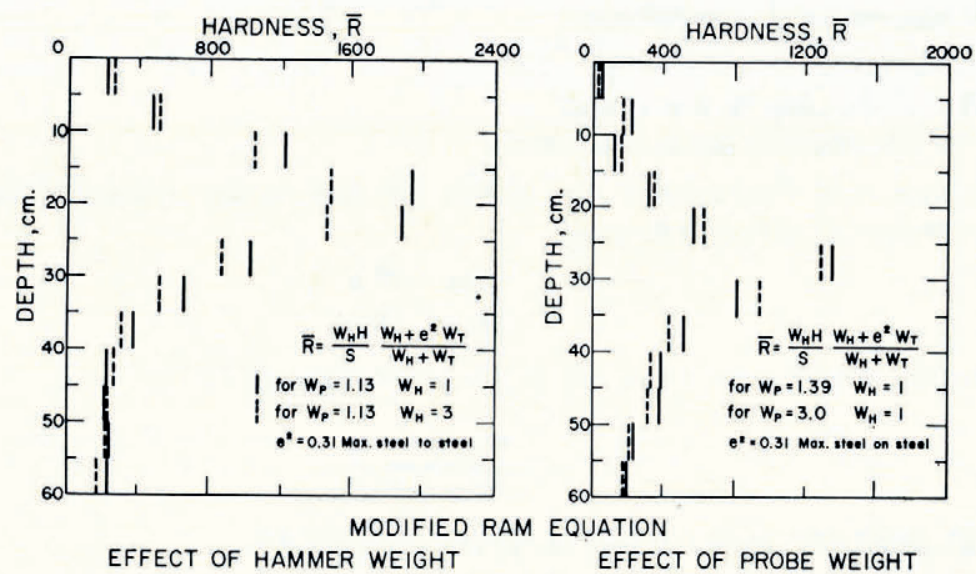

Fig. 2. Values of hardness calculated from the same data as Figure I but using the modified ram equation of Haefeli and Brandenberger (unpublished)
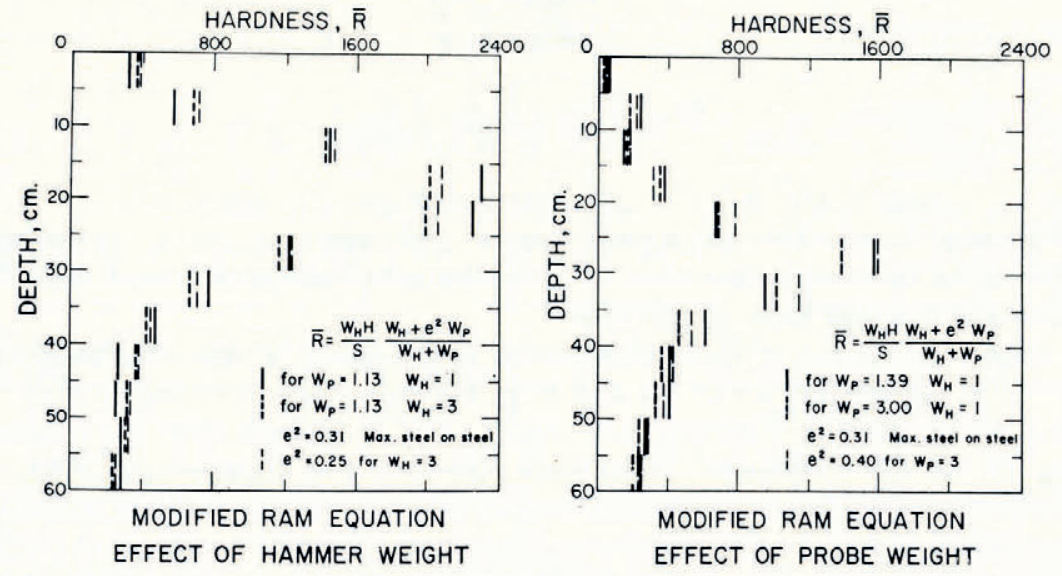

Fig. 3. Values of hardness calculated from the same data as Figure 1 but using the modified ram equation derived in this paper (the basic term of the Hiley (1925) formula). Additional points have been added to show the effect of modifying the coefficient of restitution with varying weight ratios to allow for the effect of the mass of snow outside the zone of destruction which enters into the energy exchange

Work needs to be directed towards the determination of the true maximum velocity after impact and the production of information from which mean values of the resisting force can be abstracted. Use of accelerometers is suggested. Whether it is preferable to examine the hardness equation from the view-point of acceleration during energy development and transfer remains to be seen from preliminary tests. Essentially, the mean deceleration should be proportional to the mean resistance $\bar{R} \propto W_{\mathrm{T}} \bar{a} \mid g$. This approach would eliminate the need to use the coefficient of restitution in a questionable manner. An example of an acceleration-time trace for the ram penetrating a porous material (styrofoam) is shown in Figure 4 . Integrating over the acceleration period will give the maximum velocity. Comparison of the energy from this velocity to energy from the conservation equations can provide information 


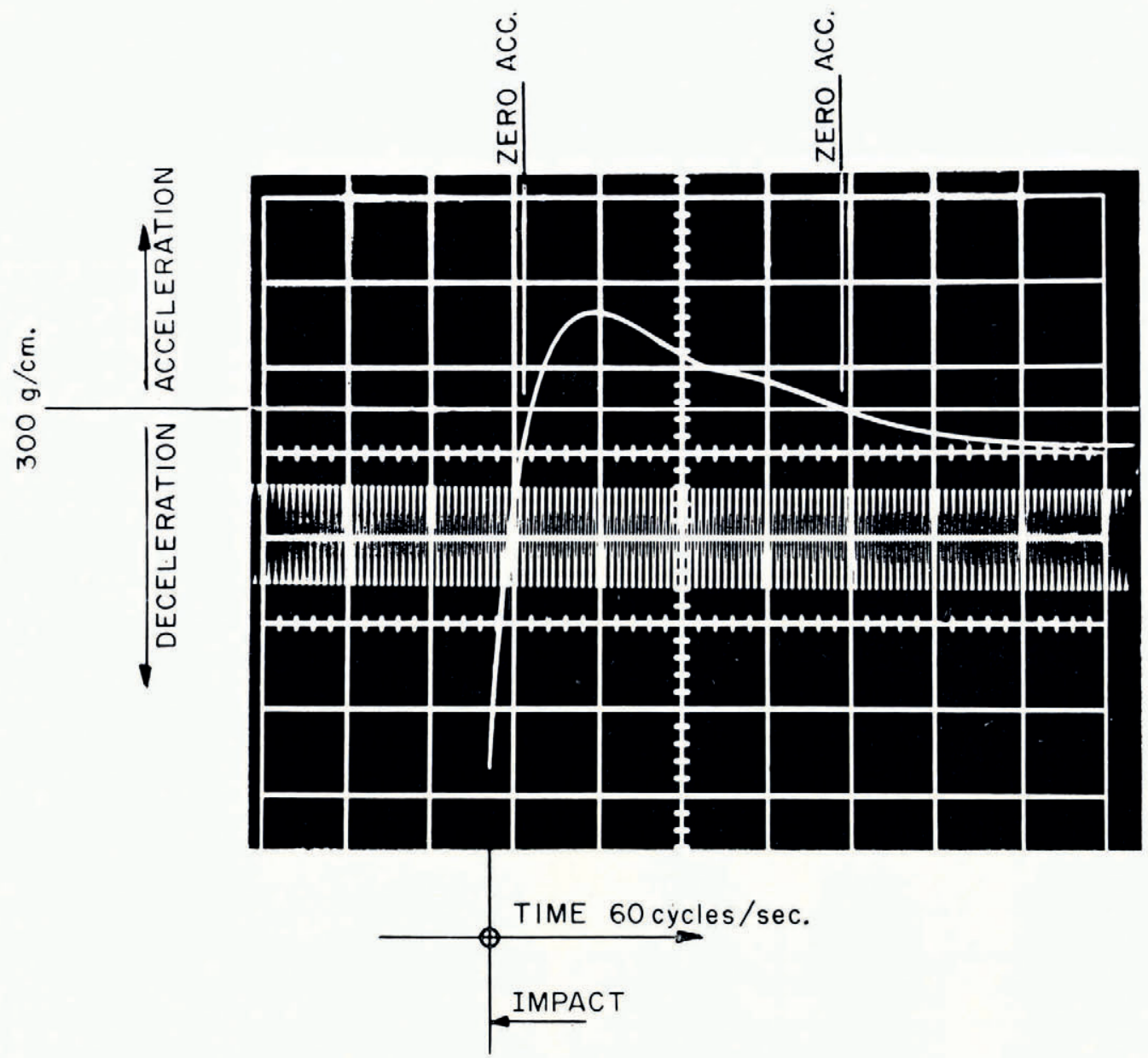

Fig. 4. Accelerometer trace for a ram entering styrofoam. The vertical scale is $300 \mathrm{~g}$ for each grid line, the horizontal scale is indicated by the 6o c./sec. trace superimposed. In the initial stage of impact the accelerometer, which is attached to the top of the hammer guide, shows an initial very rapid acceleration followed by a drop to the deceleration visible on this trace; this can only be seen on traces taken with a much more extended horizontal scale

on the magnitude of the $e^{2}$ to use in the Hiley formula. The mean force $\bar{R}$ can also be determined by estimating the mean deceleration directly from the trace.

It is a pleasure to acknowledge the assistance of F. J. Sanger of U.S. Army Cold Regions Research and Enginecring Laboratory.

MS. received I February 1966

\section{REFERENCES}

Bader, H., and others. I939. Der Schnee und seine Metamorphose, von H. Bader, R. Haefeli, E. Bucher, J. Neher, O. Eckel, C. Thams, P. Niggli. Beiträge zur Geologie der Schweiz. Geotechnische Serie. Hydrologie, Lief. 3. [Translated by J. C. van Tienhoven, U.S. Snow, Ice and Permafrost Research Establishment. Translation 14, 1954.]

Chellis, R. I95 I. Pile foundations theory design-practice. New York, McGraw-Hill. 
Haefeli, R., and Brandenberger, F. Unpublished. Ramm und Drehwiederstand. [In Faszikel Rheologie, written 1963.]

Henry, F. D. 1956. The design and construction of engineering foundations. New York, McGraw-Hill.

Hiley, A. 1925. A rational pile driving formula and its application in piling practice explained. Engineering, Vol. 119 , No. 3100 , p. 657-58; No. 3102, p. 721-22.

Niedringhaus, L. 1965. Study of the rammsonde for use in hard snow. U.S. Cold Regions Research and Engineering Laboratory. Technical Report $\mathrm{I} 53$. 